\title{
PENINGKATAN PEMAHAMAN PENGGUNAAN TRECKER PELEPAS RODA BELAKANG SEPEDA MOTOR MATIC
}

\author{
Amin Nur Akhmadi*1, faqih Fatkhurozzak ${ }^{2}$, Firman Lukman Sanjaya ${ }^{3}$ \\ 1,2 Politeknik Harapan Bersama Tegal

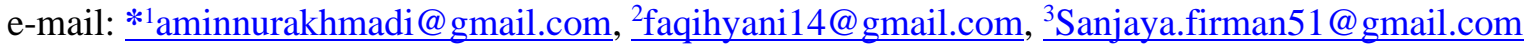

\begin{abstract}
Abstrak
Kewajiban kepada setiap Perguruan Tinggi sebagaimana dijelaskan dalam Tri Dharma Perguruan Tinggi adalah Pendidikan, Penelitian, dan Pengabdian Masyarakat. Salah satu kewajiban tersebut melaksanakan Pengabdian Masyarakat, hal ini dilaksanakan berkaitan dengan kepedulian setiap lembaga atau institusi yang bergerak dibidang Pendidikan khususnya Pendidikan Tinggi dengan mengikuti perkembangan dan kemajuan teknologi. Tujuan Pengabdian ini adalah meningkatkan pemahaman penggunaan alat trecker pelepas roda yang dapat memberikan inovasi tentang pengetahuan alat baru yang sesuai dengan Special Service Tool (SST). Metode kegiatan yang akan disampaikan kepada para mekanik di bengkel otista jaya motor Kabupaten Tegal dengan cara memberikan pembekalan pemahaman mengenai penggunaan cara menggunakan alat trecker pelepas roda dengan melalui praktek langsung pada unit sepeda motor matic pada rem tromol belakang. Selama kegiatan, para teknisi antusias mengikuti arahan dari pengabdi Hasil dari kegiatan pengabdian ini, para mekanik lebih memahami dalam penggunaan trecker Pelepas roda belakang sepeda motor matic dan meningkatnya pemahaman mengenai perawatan system pengereman terutama pada roda belakang secara aman tanpa merusak velg.
\end{abstract}

Kata kunci: Rem Tromol, Roda Belakang, Sepeda Motor, Trecker

\begin{abstract}
Obligations to every university as described in the Tri Dharma of Higher Education are Education, Research, and Community Service. One of these obligations is to carry out Community Service, this is carried out in connection with the concern of every institution or institution engaged in education, especially higher education by following developments and technological advances. The purpose of this service is to increase understanding of the use of wheel release tracker tools that can provide innovation about new tool knowledge in accordance with the Special Service Tool (SST). The method of activity that will be conveyed to mechanics at the Otista Jaya Motor workshop in Tegal Regency is by providing an understanding of how to use the wheel release tracker tool through direct practice on the automatic motorcycle unit on the rear drum brake. During the activity, the technicians enthusiastically followed the directions from the servants. As a result of this service activity, the mechanics had a better understanding of the use of automatic motorcycle rear wheel release trackers and increased understanding of braking system maintenance, especially on the rear wheels safely without damaging the wheels.
\end{abstract}

Keywords: Drum Brake, Rear Wheel, Motorcycle, Trecker

\section{PENDAHULUAN}

Kewajiban kepada setiap Perguruan Tinggi sebagaimana dijelaskan dalam Tri Dharma Perguruan Tinggi adalah Pendidikan, Penelitian, dan Pengabdian Masyarakat [1]. Salah satu kewajiban tersebut melaksanakan Pengabdian Masyarakat, hal ini dilaksanakan berkaitan dengan kepedulian setiap lembaga atau institusi yang bergerak dibidang Pendidikan khususnya Pendidikan Tinggi dengan mengikuti perkembangan dan kemajuan teknologi[2-3].

Lembaga Penelitian dan Pengabdian pada Masyarakat sangat mendukung dan merespon akan kepedulian tersebut dengan menyelenggarakan kegiatan Pengabdian 
Masyarakat berupa Peningkatan Pemahaman Penggunaan Trecker Pelepas Roda Belakang Sepeda Motor Matic.

Potensi penggunaan alat-alat bengkel kerap tidak sesuai dengan SST dan berkenaan dengan pekerjaan kecepatan dalam bekerja yang meliputi: servis karburator, system bahan bakar, sistem kemudi, sistem kelistrikan, sehingga dalam pekerjaan perbengkelan sering terjadi gangguan keterlambatan dalam menangani konsumen seperti tune up seharusnya ditangani secara cepat tapi dengan kurangnya alat-alat maka pekerjaan menjadi terlambat. Sementara itu karena latar belakang pendidikan dan pengalaman kerja civitas akedemika yang meliputi para dosen, teknisi dan mahasiswa yang beragam menyebabkan pengelolaan bengkel tempat kerja kurang memadai, sehingga alat-alat yang di bengkel kerja dan lingkungan, mengancam kurangnya konsumen yang akan dating ke bengkel untuk servis [4].

Kelurahan debong kidul dengan kecamatan tegal selatan dengan jumlah penduduknya mencapai 3556 jiwa, dan kebanyakan masyarakatnya berprofesi sebagai pekerja dan wirausaha. Kelurahan debong kidul lokasinya di daerah perempatan grogol ke selatan tepatnya di jalan cik ditiro ke selatan dekat dari perkotaan terutama jalan yang menghubungkan kota dan kabupaten, membuat masyarakat semakin senang dalam melakukan kegiatan sehari-hari apalagi jika motor atau kendaraan yang dimiliki rusak dan tidak dapat memperbaiki sendiri, karena kurangnya pengetahuan tentang perbaikan sepeda motor sehingga untuk memperbaiki sepeda motor yang rusak harus ke dealer yang sesuai dengan merk motornya dan biaya yang mahal[5].

Tabel 1. Dimensi Tromol Sepeda motor

\begin{tabular}{|c|c|c|c|}
\hline No & Tromol & Type & $\begin{array}{c}\text { Dimensi } \\
\text { Tromol }\end{array}$ \\
\hline 1 & Velg Racing & Bebek & $18 \mathrm{~cm}$ \\
\hline 2 & Velg Tromol & Bebek & $19.5 \mathrm{~cm}$ \\
\hline 3 & Velg Racing & Sport & $18.5 \mathrm{~cm}$ \\
\hline 4 & Velg Tromol & Sport & $19.5 \mathrm{~cm}$ \\
\hline 5 & Velg Racing & matic & $20 \mathrm{~cm}$ \\
\hline 6 & Velg tromol & Matic & $22 \mathrm{~cm}$ \\
\hline
\end{tabular}

\section{METODE}

Metode pelaksanaan peningkatan pemahaman penggunaan trecker pelepas roda belakang sepeda motor sebagai berikut : Pengabdian ini dilaksanakan pada pukul 09.00 s.d. 12.00 WIB hari sabtu dan minggu $14-15$ November 2020 di Bengkel Oto Iskandardinata Kelurahan kidul Kecamatan Tegal Selatan Kota Tegal. Peserta yang hadir sebanyak 20 orang, terdiri dari para mekanik bengkel dan pelanggan bengkel. Pengabdi mengajarkan cara meningkatkan pemahaman penggunaan trecker pelepas roda belakang sepeda motor matic kepada mekanik kawasan kelurahan debong kidul Kecamatan Tegal Selatan Kota Tegal.

Metode kegiatan yang akan disampaikan kepada para mekanik dibengkel otista jaya motor Kabupaten Tegal bentuk peningkatan 
pemahaman penggunaan trecker pelepas roda belakang sepeda motor matic. Para mekanik diberi pembekalan pemahaman penggunaan bagaimana cara menggunakan alat trecker pelepas roda dengan melalui praktek langsung pada unit sepeda motor matic pada rem tromol belakang matic. Mekanik juga dibekali bagaimana cara perawatan rem tromol belakang pada sepeda motor matic dengan perawatan tersebut maka setiap rem tromol pada sepeda motor matic akan selalu terawatt bersih dan awet pemakaianya. Kegiatan ini dilaksanakan selama 2 hari.

\section{HASIL DAN PEMBAHASAN}

Berdasarkan pengamatan langsung di bengkel sepeda motor otista kelurahan debong kidul telah dilaksanakan pemahaman penggunaan treker pelepas roda belakang motor matic sesuai SOP kepada para mekanik bengkel tersebut, maka kegiatan pengabdian masyarakat ini menghasilkan hasil sebagai berikut:

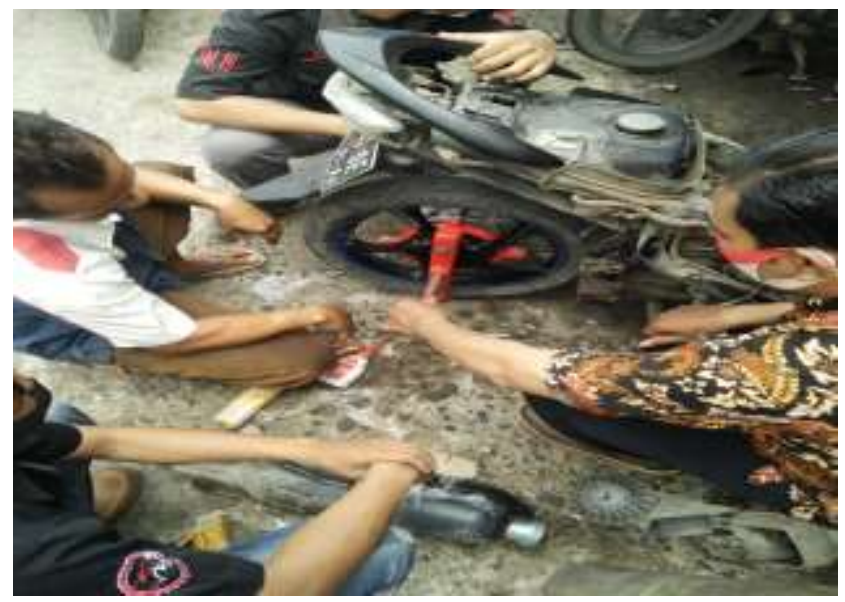

Gambar 1. Mengarahkan baut pendorong di center rem tromol

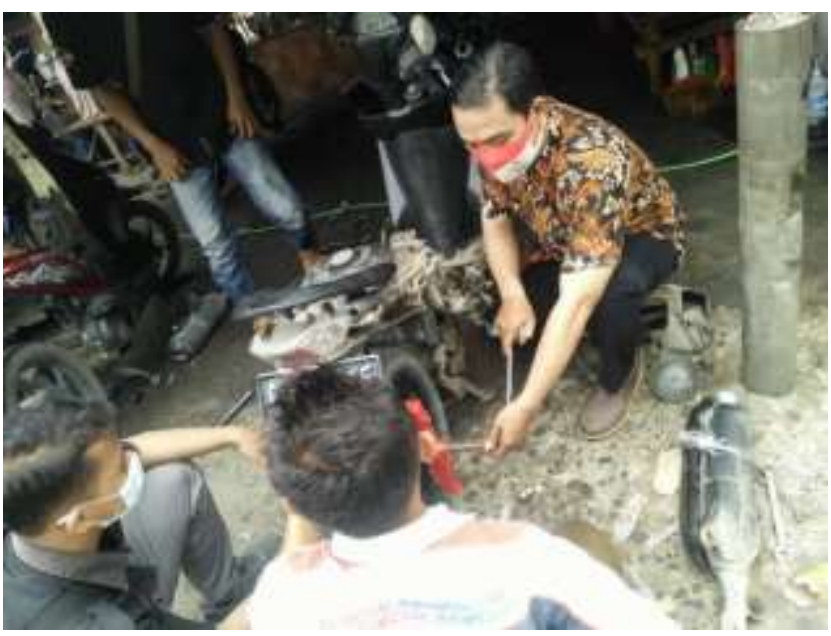

Gambar 2. Ketua PKM memperagakan cara membuka dengan memutar dengan kunci

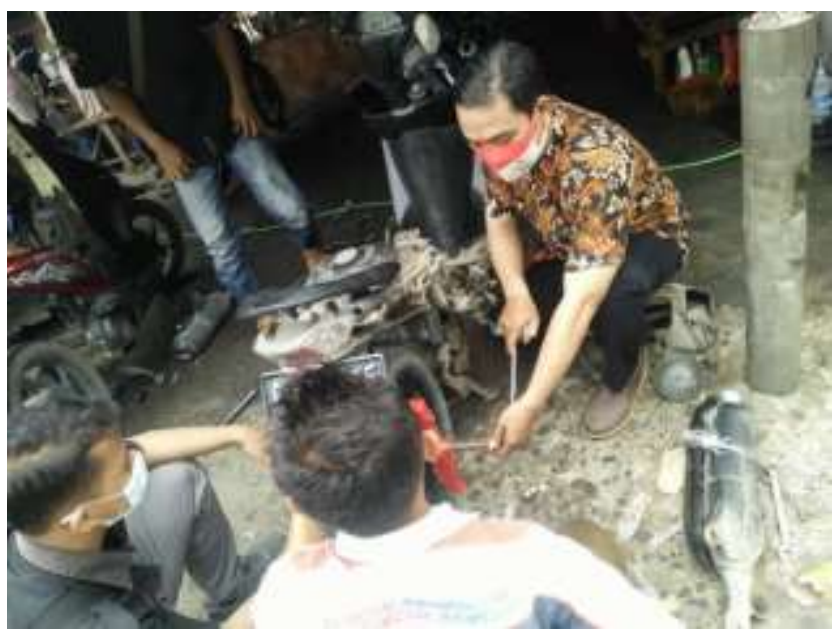

Gambar 2. Ketua PKM memperagakan cara membuka dengan memutar dengan kunci

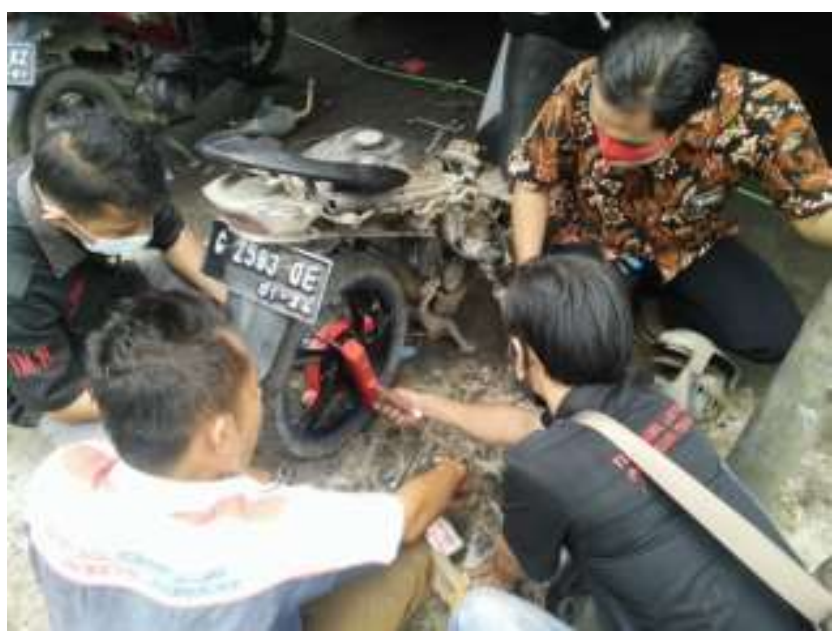

Gambar 3. Mahasiswa membantu pemasangan baut penahan 


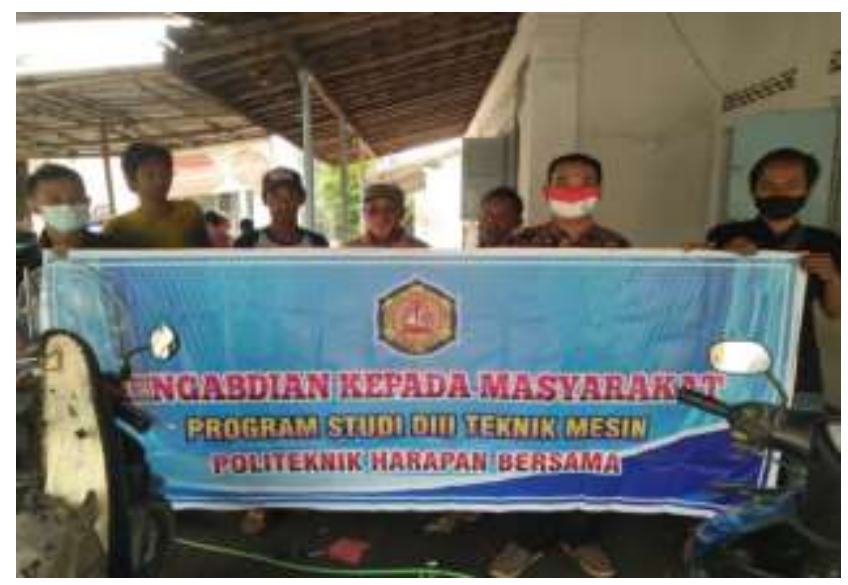

Gambar 4. Dokumentasi bersama mekanik bengkel

Dari kegiatan ini menghasilkan sebagai berikut :

1. Meningkat sumber daya manusia manusia khususnya mekanik bengkel motor yang memiliki keahlian, ketrampilan, pengetahuan, serta etos kerja yang sesuai dengan tuntutan dalam perawatan sepeda motor khususnya pada perawatan system pengereman terutama pada roda belakang.

2. Mengenalkan kepada para mekanik bengkel adanya alat bantu untuk memudahkan membuka velg tromol belakang roda sepeda motor pada saat untuk membersihkan / mengganti kampas rem tromol secara aman tanpa merusak vleg racing.

3. Memperkenalkan peralatan multi fungsi yang efisien dipakai secara umum khususnya pada bengkel sepeda motor. pemahaman penggunaan treker pelepas roda belakang sepeda motor matic sebagai media alat bantu yang membantu memudahkan melepas dan membuka pada waktu ingin melepas velg racing tromol pada bengkel otista jaya motor kelurahan debong kidul dapat berjalan lancar, peningkatan pemahaman penggunaan treker pelepas velg roda ban belakang sepeda motor matic nyata-nyata dibutuhkan bagi para mekanik bengkel dan konsumen pelanggan bengkel.

Kebanyakan para mekanik bengkel dan pelanggan mengeluhkan kurangnya peralatan yang sesuai dengan apa yang akan dikerjakan untuk membuka melepaskan velg dari rumah chasis body rem secara cepat dan aman. Pelanggan menyadari sepenuhnya bahwa peralatan pelepas tromol pada bengkel sepeda motor yang mereka datangi kurangnya peralatan yang sesuai dan memadai. Bengkel otista jaya motor bertanggung tanggung jawab atas kegiatan peningkatan pemahaman penggunaan trecker pelepas velg tromol sebagai media pembuka ,sehingga bengkel harus bisa menjaga pelayanan konsumen pada pelanggannya, untuk itu diperlukan pelatihan tindakan yang meningkatkan kualitas pelayanan perbengkelan dengan menerapkan model pelatihan penggunaan peralatan yang inovatif.

Hasil pelatihan akan banyak bermanfaat bagi orang lain dalam bentuk pelatihan secara langsung kepada para mekanik dan konsumen pelanggan bengkel, Oleh karena itu para mekanik dan pelanggan banyak dapat manfaat yang 
diperoleh dari pelatihan ini untuk meningkatkan kemampuan kinerja dalam pelayanan perbengkelan.

\section{SIMPULAN}

Dari hasil tersebut juga dapat disimpulkan bahwa dengan adanya kegiatan pengabdian masyarakat dibengkel sepeda motor otista jaya motor kelurahan debong kidul dengan memberikan pengetahuan dan inovasi baru terhadap peralatan untuk membantu mempermudah melepaskan velg tromol belakang sepeda motor matic yang efisien tanpa merudak body velg. Selain itu, kegiatan ini mempermudah kinerja mekanik dalam pelayanan service merawat dalam membuka rem pada rem tromol belakang, dengan adanya alat tersebut sehingga membuat pelanggan puas akan kinerjanya pada komponen kendaraan.

\section{SARAN}

Dari hasil kegiatan pengabdian kepada masyarakat ini, timbul beberapa saran yaitu perlu kiranya dilakukan pelatihan kepada mekanik bengkel, khususnya mekanik yang kompeten dalam hal menguasai semua trouble sepeda motor dalam hal membongkar / melepas dan memperbaiki komponen-komponen yang sulit dijangkau oleh tangan. Pada saat memasang alat treker pada velg tromol belakang dipastikan memasang kedua sisi baud pengunci samping kiri dan kanan, memasang baut poros pendorong presisi dengan poros roda. Dan disarankan untuk memutar dengan kunci ring supaya dorongan tarik tekan lebih kuat dan cepet lepas dari rumah rem.

\section{DAFTAR PUSTAKA}

[1] D. Setiawan, H. D. Saputra, and M. Chaniago, "Pelatihan Keterampilan Membangun Bisnis (Wirausaha) Bengkel Sepeda Motor Secara Mandiri Bagi Siswa SMK," Suluah Bendang J. Ilm. Pengabdi. Kpd. Masy., vol. 20, no. 1, p. 21, 2019, doi: 10.24036/sb.0330.

[2] S. Syarifudin and S. Syaiful, "Pengaruh Penggunaan Energi Terbarukan Butanol Terhadap Penurunan Emisi Jelaga Mesin Diesel Injeksi Langsung Berbahan Bakar Biodiesel Campuran Solar Dan Jatropa," Infotekmesin, vol. 10, no. 1, pp. 18-22, 2019 , doi:

10.35970/infotekmesin.v10i1.20.

[3] A. Akhmadi, M. T. Qurohman, and S. Syarifudin, "Peningkatan Kompetensi Auto CAD Bagi Siswa SMK Ma'arif NU Talang Kabupaten Tegal,” J. Pengabdi. Masy. Progresif Humanis Brainstorming, vol. 1, no. 1, pp. 15-21, 2017, doi: 10.30591/japhb.v1i1.683.

[4] P. Hargiyarto, "Analisis Kondisi Dan Pengendalian Bahaya Di Bengkel/ Laboratorium Sekolah Menengah 
Kejuruan," J. Pendidik. Teknol. dan Kejuru. UNY, vol. 20, no. 2, p. 163984, 2015, doi: 10.21831/jptk.v20i2.3319.

[5] BPS KOTA TEGAL, "Indo_12_12408421.".

[6] S. Suherman, N. Nurhapsa, and I. Irmayani, "Pemberdayaan Masyarakat Tani di Desa Batu Mila Melalui Pelatihan Pembuatan Pupuk Organik dari Limbah Pertanian," Pros. Semnas 2018 Sinergitas Multidisiplin Ilmu Pengetah. dan Teknol. Vol 1, vol. 1, no. April, pp. 119-124, 2018. 